\title{
Composite sandwich impact response: experimental and numerical analysis
}

\author{
Filippo Cucinotta, Felice Sfravara \\ Department of Engineering, University of Messina, Italy \\ filippo.cucinotta@unime.it, http://orcid.org/0000-0002-0304-4004 \\ fsfravara@unime.it,bttp://orcid.org/0000-0003-3922-8494 \\ Paolo Neri, Armando Razionale \\ Department of Civil and Industrial Engineering, University of Pisa, Italy \\ paolo.neri@dici.unipi.it, bttp:/ / orcid.org/ 0000-0003-0730-0893 \\ armando.razionale@dici.unipi.it, bttp://orcid.org/0000-0001-7110-3857
}

\begin{abstract}
The use of composite materials allows to have a great flexibility in terms of mechanical and physical characteristics. One of the most used composite structure in naval field, is the sandwich, which is composed by a stacking sequence of different plies. The designer, in preliminary phase, must handle a great quantity of degree of freedom (types of materials, orientation of the fibres, position along the stack, thickness, etc.) in order to reach the best compromise between mechanical behaviour, environmental impacts and production costs. Finite Element analysis represents a useful tool in order to optimize all these parameters and to estimate the outcome of experimental tests at design stage. The main goal of this work is to develop and to validate a FE model for the simulation of a particular family of composites, widely used in naval field and, in particular, in High Speed Crafts and powerboats. The first part of the paper concerns the experimental tests on two different types of sandwich specimens. Two families of tests were conducted: fourpoint bending tests and impact drop tests. The second part of the paper focuses on the validation of a FE model for both experimental setups.
\end{abstract}

KEYWORDS. Finite Element; Lightweight composites; Sandwich composites; Offshore powerboats; Impact tests.

\section{open 2 Access}

Citation: Cucinotta, F., Sfravara, F., Neri, N., Razionale, A., Composite sandwich impact response: experimental and numerical analysis, Frattura ed Integrità Strutturale, 47 (2019) 367-382.

Received: 05.11.2018

Accepted: 03.12.2018

Published: 01.01.2019

Copyright: (C) 2019 This is an open access article under the terms of the CC-BY 4.0, which permits unrestricted use, distribution, and reproduction in any medium, provided the original author and source are credited.

\section{INTRODUCTION}

7 he great potentiality of the composite materials is now largely documented and exploited in each field of engineering. The importance of the composite material with respect to the other basic materials (metals, ceramics, polymers) has been presented by Ashby [1]. The importance of the no-metals materials is steadily increasing with respect to the metal ones. Usually the composite materials are used because they have a great flexibility in terms of mechanical and physical properties. Gibson [2] explains the main advantages in the use of this materials and also the theory for solving mechanical problems at design stage. The main potentiality of composite materials is the high strength-to-weight ratio and the high 
stiffness-to-weight ratio. These parameters are highly influenced by the type of fibres used to produce the composite. A general overview of these parameters in function of the mass density is shown by Kelly [3]. In many fields of engineering there is the need to reduce the weight in order to reduce the energy consumption, which impacts in the air pollution. For this reason, the mechanical properties of composites are of great interest in many engineering fields. Aeronautical engineering proved to be the pioneer in the use of composite materials. In this field the use of composites started many years ago, and the principal applications are shown by Soutis [4]. With the increase of the requirements in terms of weight and pollution performances, also automotive and naval engineers started to use these materials in different ways. An example is in the production of automotive components: Ding et al. [5] showed that with the use of the composite materials in a rear bumper beam it is possible to achieve a reduction of the weight of about $40 \%$ keeping the same performance requirements. In the naval field, the use of composite material is isolated to the yacht design. Kimpara showed the developments and the increase of use of these materials in this field in the last years [6]. The reduction of environmental impact in the usage phase of the product represents another important aspect directly linked to the reduction of weight. Timmis et al. [7] proposed an analysis aimed at assessing the reduction of environmental impact thanks to the use of composite materials in the aviation field. The study has been conducted for a Boeing 787 and successively expanded to the global feet. The use of composite materials was proven to reduce the $\mathrm{CO}_{\mathrm{x}}$ and $\mathrm{NO}$ x emissions of about 20\% [7]. Also, in the automotive field the stringent rules for pollution pushed the engineers to use composite materials to reduce environmental impact. Witik et al. [8] proposed an environmental and costs comparison between carbon fibres, magnesium and steel materials for a representative component of a car, i.e. the bulkhead between the passengers compartment and luggage space. The final results showed that the weight reduction sometimes does not improve the environmental performance because of the disposal process of synthetic fibres. For this reason, many researchers pushed the studies on the use of natural fibres in automotive components. A review of all green useful fibres for automotive applications is reported by Koronis et al. [9]. The use of this type of fibre allows to reduce the environmental impact in production phase and successively in usage phase, as shown by Boland et al. [10]. The environmental benefits produced by the application of composites is taken into account also in mechanical industry. Barone et al. [11] shown the different impacts between utility poles manufactured in steel and composite, highlighting that the weight reduction achieved through glass fibres led to an important reduction of the environmental impact.

However, there are also critical aspects in the use of composite materials. The manufacturing process of a product with composite material is complex, requiring highly skilled workers. The mechanical properties of each product are highly influenced by the manufacturing process. Kim et al. [12] shown the difference of the mechanical properties between the same product manufactured with two different process technologies (hand lay-up and vacuum infusion), highlighting that the samples manufactured with vacuum infusion have larger ultimate strength and modulus in both tension and compression tests than the hand lay-up ones.

Composite materials have different failure modes and so it is very complex to predict the type of failure and the evolution of damage during operations [13]. In order to give general laws for the prediction of the possible failure modes many researches focused on experimental tests. A characterization of a honeycomb sandwich with aramid fibres and aluminium core is proposed by Belouettar et al. [14]. The study concerned the evaluation of mechanical properties of the sandwich during four-points bending tests in static and dynamic conditions. Other tests has been conducted by Manalo et al. [15]: the composite sandwich beams under study were subject to four-points static bending test to determine their strength and failure mechanisms in the flatwise and edgewise positions. Another crucial aspect is represented by the response of the composite material to dynamic loading. Many researchers developed new indexes in order to quantify the capacity of the sandwich composite to absorb energy during the low velocity impacts [16]. Also the influence of the thickness of the laminates has been evaluated by Belingardi et al. [17]. In the last years, many researchers, in parallel to the experimental tests, proposed also numerical simulations. A validation of this approach is very important for structures in composite materials in order to have a useful tool in preliminary design. Russo et al. [18] proposed a numerical investigation using non-linear simulations and accurate failure criteria with an experimental validation. Also Manalo et al. [15] used the experimental tests for the validation of a numerical approach developed with a commercial software. Hassan et al. [19] investigated the potentiality in the use of numerical simulations for the analysis of impact tests on composite material. In the aforementioned works, the main reason of the discrepancies between experimental and numerical simulations is determined by the insufficient information on actual mechanical properties of the materials.

The main goal of this work is to develop a Finite Element (FE) model for the simulation of a particular family of composite materials, widely used in naval field and, in particular, in the High Speed Craft and motorboats field. The model validation was achieved through the comparison with experimental four-points bending tests and impact drop tests at different energy levels. Two different sandwich specimens were considered, having a different lay-up sequence. The first validation concerns the four-points bending test in terms of load-displacement curves. The second validation concerns the impact drop test 
with three different energy levels (20 J, $40 \mathrm{~J}, 60 \mathrm{~J}$ ), comparing again the load-displacement curve. A complete description of the considered materials (along with the mechanical properties of each specimen), a full description of the experimental procedure and a step-by-step description of the numerical set-up are reported.

\section{MATERIALS AND METHODS}

\section{Tested samples}

$\checkmark$ wo different types of sandwich were considered, widely used for racing boats manufacturing. The sandwiches under investigation have been produced by two different racing team for the same competition category of the UIM (Unione Internationale Motonautique). Firstly, a four-point bending test was performed on both specimen types. Then, in a second campaign, drop impact tests with increasing energy levels were performed. The results of these experimental tests were finally exploited for FE model validation. The two sandwiches have been both manufactured with the hand layup technique. The general specimen for the bending test was $800 \mathrm{~mm}$ x $100 \mathrm{~mm}$ with a total thickness depending on the stacking sequence of the laminates, according to the rule 508.03 of the UIM offshore rules 2017. The general specimen for the impact drop test was $100 \mathrm{~mm} \times 100 \mathrm{~mm}$ and total thickness depending on the stacking sequence of the laminates; in this case, since there is not a reference rule, the impact parameters have been chosen according to ASTM D-07136 standard, as in Cucinotta et al. [20]. The two principal directions for defining engineering constants (Orientation of the fibres, Young Modulus, Poisson coefficient and Shear Modulus) were depicted with x (direction 1) and y (direction 2) as shown in Fig. 1. The two types of sandwich have been called, respectively A and B.
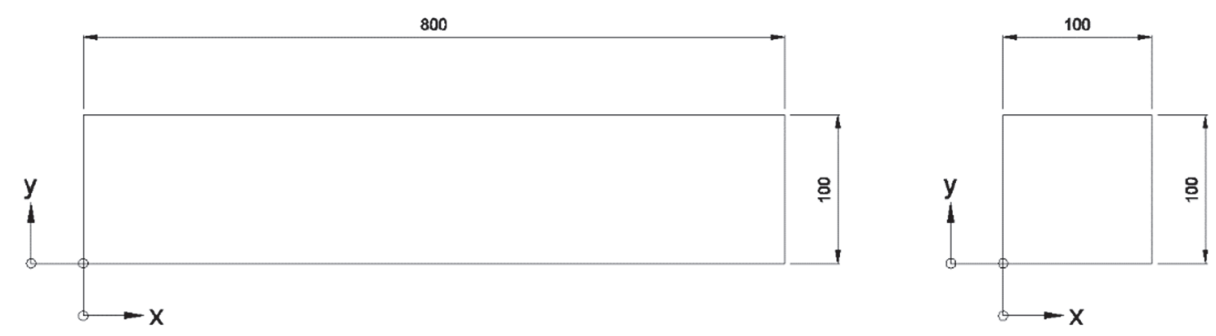

Figure 1: Specimen dimensions and reference system used for bending test (left) and for impact test (right).

The two materials, called A sandwich and B sandwich, are designed for the same competition class by different builders. However, the main characteristics are a little different, as highlighted in the Tab. 1.

\begin{tabular}{rcc}
\hline & A Sandwich & B Sandwich \\
Total thickness $[\mathrm{mm}]$ & 35.9 & 33.0 \\
Weight area density $\left[\mathrm{kg} / \mathrm{m}^{2}\right]$ & 13.2 & 7.7 \\
\hline
\end{tabular}

Table 1: General characteristics of Specimen A.

The A sandwich is composed by two different exterior laminated skins and central homogeneous core. The general characteristics of each ply inside the sandwich are shown in Tab. 2. The total thickness of the A sandwich is about $35.9 \mathrm{~mm}$.

\begin{tabular}{lccl}
\hline Ply & Orientation $\left[{ }^{\circ}\right]$ & Wet thickness $[\mathrm{mm}]$ & Dry mass density \\
E-Glass & {$[0 / 90]$} & 0.48 & $4.50 \mathrm{E}-07\left[\mathrm{~kg} / \mathrm{mm}^{2}\right]$ \\
Carbon & {$[-45 / 45]$} & 0.45 & $4.07 \mathrm{E}-07\left[\mathrm{~kg} / \mathrm{mm}^{2}\right]$ \\
Carbon & {$[0 /-45 /+90 /+45]$} & 1.71 & $8.07 \mathrm{E}-07\left[\mathrm{~kg} / \mathrm{mm}^{2}\right]$ \\
Carbon & {$[-45 /+45]$} & 0.45 & $4.07 \mathrm{E}-07\left[\mathrm{~kg} / \mathrm{mm}^{2}\right]$ \\
Core & Gurit-M130 & 30.00 & $1.40 \mathrm{E}-07\left[\mathrm{~kg} / \mathrm{mm}^{3}\right]$ \\
Carbon & {$[-45 /+45]$} & 0.45 & $4.07 \mathrm{E}-07\left[\mathrm{~kg} / \mathrm{mm}^{2}\right]$ \\
Carbon & {$[0 /-45 /+90 /+45]$} & 1.71 & $8.07 \mathrm{E}-07\left[\mathrm{~kg} / \mathrm{mm}^{2}\right]$ \\
Carbon & {$[-45 /+45]$} & 0.45 & $4.07 \mathrm{E}-07\left[\mathrm{~kg} / \mathrm{mm}^{2}\right]$ \\
Kevlar & {$[0 / 90]$} & 0.26 & $1.75 \mathrm{E}-07\left[\mathrm{~kg} / \mathrm{mm}^{2}\right]$ \\
\hline
\end{tabular}

Table 2: General characteristics of A sandwich. 
The external plies are respectively in E-Glass and Kevlar, as shown in Fig. 2 (a) and (b), while the internal ones are in Carbon with different orientations. The core material is a structural foam with a Styrene acrylonitrile foam (SAN) polymer base. This type of foam guarantees high toughness and high impact resistance and it has a very good compromise between low weight and high shear strength.

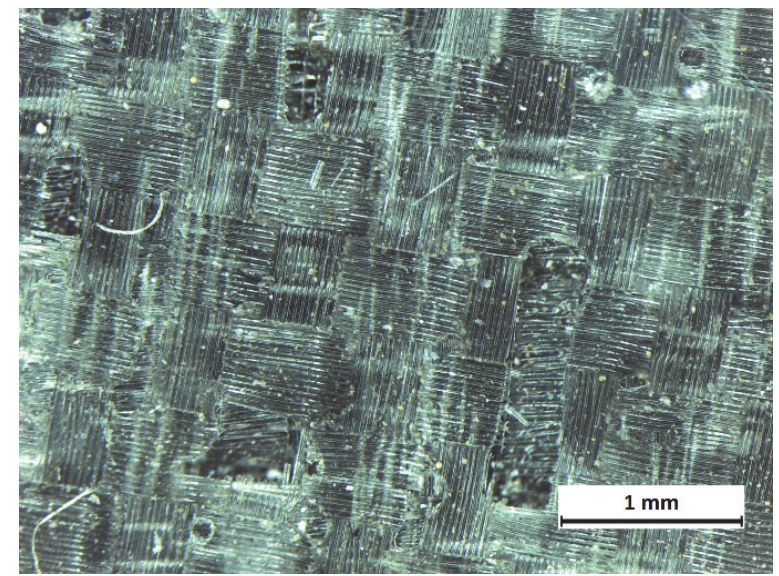

(a)

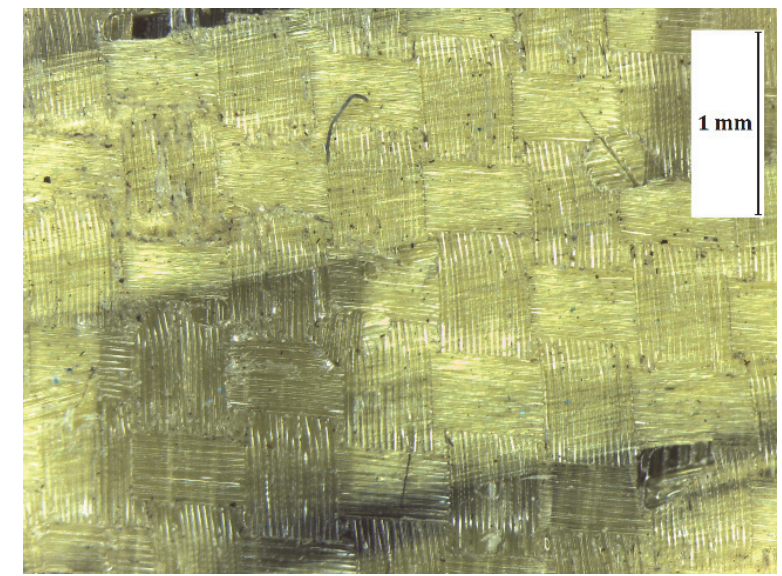

(b)

Figure 2: External skins of A sandwich, the E-Glass skin (a) and the Kevlar skin (b) (zoom factor to 32x).

Fig. 3 shows two microscope pictures along the thickness of the A sandwich corresponding to the E-Glass side and the Kevlar side (Fig. 3(a) and (b) respectively).

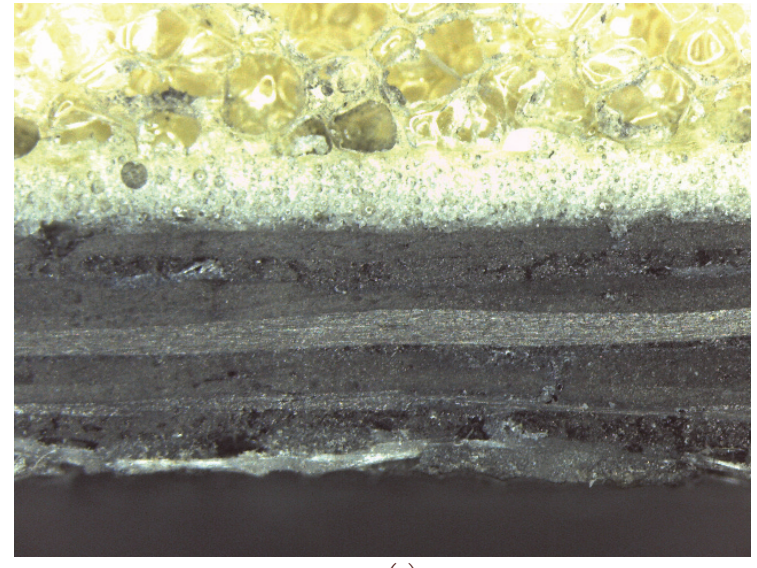

(a)

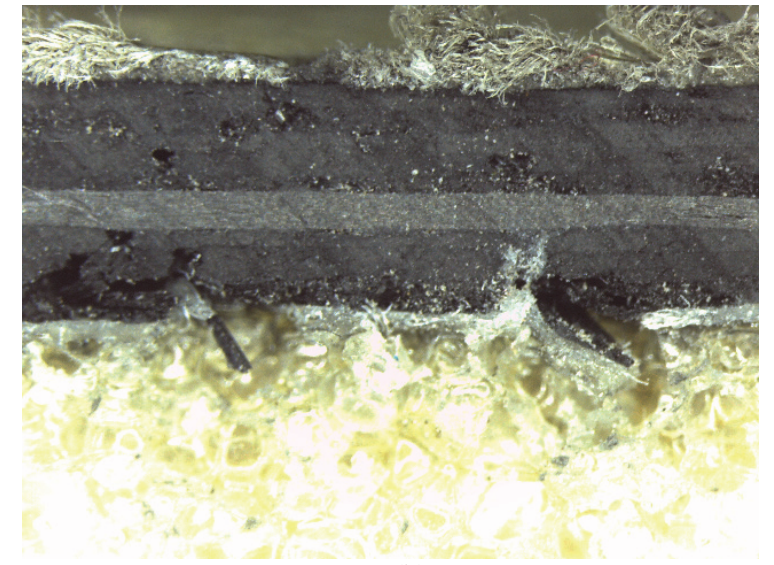

(b)

Figure 3: Microscope pictures along the thickness of A sandwich, the E-Glass side (a) and the Kevlar side (b) (zoom factor to 32x).

The mechanical properties for the consitutive materials of the A sanwich are reported in Tab. 3, while the weight percentage of the reinforcement materials with respect to the total are reported in Tab. 4. It was then possible to exploit the well known rule of mixtures to calculate the mechanical properties of the undirectional impregnated fiber. The resutls are reported in Tab. 5.

\begin{tabular}{lccccc}
\hline Basic materials & $\sigma_{\mathrm{R}}\left[\mathrm{N} / \mathrm{mm}^{2}\right]$ & $\mathrm{E}\left[\mathrm{N} / \mathrm{mm}^{2}\right]$ & $\mathrm{G}\left[\mathrm{N} / \mathrm{mm}^{2}\right]$ & $\nu$ & $\varrho\left[\mathrm{kg} / \mathrm{mm}^{3}\right]$ \\
E-Glass & 1500 & 72400 & 30170 & 0.20 & $2.56 \mathrm{E}-06$ \\
Carbon & 4070 & 248000 & 103330 & 0.20 & $1.80 \mathrm{E}-06$ \\
Core M130 & 2.85 & 180 & 60 & 0.33 & $1.40 \mathrm{E}-07$ \\
Kevlar & 3620 & 131000 & 48520 & 0.35 & $1.45 \mathrm{E}-06$ \\
Resin & 110 & 3400 & 1310 & 0.30 & $1.20 \mathrm{E}-06$ \\
\hline
\end{tabular}

Table 3: Mechanical properties of the basic materials. 


\begin{tabular}{lrrr}
\hline & E-Glass & Carbon & Kevlar \\
\hline $\mathrm{w}_{\mathrm{f}}$ & 0.50 & 0.59 & 0.50 \\
$\mathrm{w}_{\mathrm{m}}$ & 0.50 & 0.41 & 0.50 \\
$\mathrm{v}_{\mathrm{f}}$ & 0.32 & 0.49 & 0.45 \\
$\mathrm{v}_{\mathrm{m}}$ & 0.68 & 0.51 & 0.55 \\
\hline
\end{tabular}

Table 4: Weight and Volume percentage of fibres and resin.

\begin{tabular}{lccccccc}
\hline $\begin{array}{l}\text { Unidirectional } \\
\text { lamina }\end{array}$ & $\sigma_{\mathrm{R} 11}\left[\mathrm{~N} / \mathrm{mm}^{2}\right]$ & $\sigma_{\mathrm{R} 22}\left[\mathrm{~N} / \mathrm{mm}^{2}\right]$ & $\begin{array}{c}\mathrm{E} 1 \\
{\left[\mathrm{~N} / \mathrm{mm}^{2}\right]}\end{array}$ & $\begin{array}{c}\mathrm{E} 2 \\
{\left[\mathrm{~N} / \mathrm{mm}^{2}\right]}\end{array}$ & $\begin{array}{c}\mathrm{G} 12 \\
{\left[\mathrm{~N} / \mathrm{mm}^{2}\right]}\end{array}$ & $v_{12}$ & $v_{21}$ \\
E-Glass & 553.62 & 62.04 & 25420 & 4890 & 1880 & 0.27 & 0.05 \\
Carbon & 2048.92 & 47.07 & 123160 & 6580 & 2530 & 0.25 & 0.01 \\
Kevlar & 1699.43 & 51.25 & 61180 & 6080 & 2340 & 0.32 & 0.03 \\
\hline
\end{tabular}

Table 5: Mechanical properties of unidirectional laminas.

The mechanical properties of a single cross-ply laminate are function of the orientation and stacking sequence of the plies inside the laminate. It is possible to calculate these mechanical properties and to know the main engineering characteristics along all possible orientation of the laminate by exploiting the lamination theory. Fig. 4 from (a) to (h) shows the differences between the mechanical properties of the unidirectional fibres and the resulting properties of the obtained cross-ply laminates inside the A sandwich. In the case of a specimen A, Tab. 6 resumes the mechanical properties for each oriented cross-ply laminate.

The second sandwich, called B sandwich, has been produced with different plies of carbon, as shown in Fig. 5, having a symmetric distribution of the plies along the thickness. The core material is the same typology of the A sandwich but with slightly different density. The general characteristics of each laminate inside the sandwich are shown in Tab. 7. The total thickness of the specimen $B$ is $33 \mathrm{~mm}$.

\begin{tabular}{lcccccc}
\hline Cross-ply laminate & $\sigma_{\mathrm{R} 11}\left[\mathrm{~N} / \mathrm{mm}^{2}\right]$ & $\sigma_{\mathrm{R} 22}\left[\mathrm{~N} / \mathrm{mm}^{2}\right]$ & $\begin{array}{c}\mathrm{E} 1 \\
{\left[\mathrm{~N} / \mathrm{mm}^{2}\right]}\end{array}$ & $\begin{array}{c}\mathrm{E} 2 \\
{\left[\mathrm{~N} / \mathrm{mm}^{2}\right]}\end{array}$ & $\begin{array}{c}\mathrm{G} 12 \\
{\left[\mathrm{~N} / \mathrm{mm}^{2}\right]}\end{array}$ & $v_{12}$ \\
E-Glass [0/90] & 307.8 & 307.8 & 15250 & 15250 & 1880 & 0.09 \\
Carbon [-45/45] & 801.2 & 801.2 & 9400 & 9400 & 31700 & 0.68 \\
Carbon [0/-45/90/45] & 924.6 & 924.6 & 45260 & 45260 & 17120 & 0.44 \\
Kevlar [0/90] & 875.3 & 875.3 & 33800 & 33800 & 2340 & 0.06 \\
\hline
\end{tabular}

Table 6: Mechanical properties for each laminate in A sandwich.

\begin{tabular}{lccc}
\hline Ply & Orientation $\left[^{\circ}\right]$ & Wet thickness $[\mathrm{mm}]$ & Dry mass density \\
Carbon & $-45 /+45$ & 0.50 & $4.07 \mathrm{E}-07\left[\mathrm{~kg} / \mathrm{mm}^{2}\right]$ \\
Carbon & $0 / 90$ & 0.50 & $4.07 \mathrm{E}-07\left[\mathrm{~kg} / \mathrm{mm}^{2}\right]$ \\
Carbon & $-45 /+45$ & 0.50 & $4.07 \mathrm{E}-07\left[\mathrm{~kg} / \mathrm{mm}^{2}\right]$ \\
Core M100 & Gurit-M100 & 30.00 & $1.07 \mathrm{E}-07\left[\mathrm{~kg} / \mathrm{mm}^{3}\right]$ \\
Carbon & $-45 /+45$ & 0.50 & $4.07 \mathrm{E}-07\left[\mathrm{~kg} / \mathrm{mm}^{2}\right]$ \\
Carbon & $0 / 90$ & 0.50 & $4.07 \mathrm{E}-07\left[\mathrm{~kg} / \mathrm{mm}^{2}\right]$ \\
Carbon & $-45 /+45$ & 0.50 & $4.07 \mathrm{E}-07\left[\mathrm{~kg} / \mathrm{mm}^{2}\right]$ \\
\hline
\end{tabular}

Table 7: General characteristics of B sandwich. 


\section{E-glass}

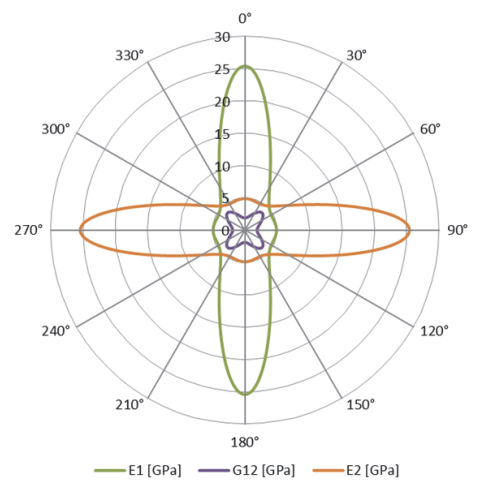

(a) - unidirectional lamina

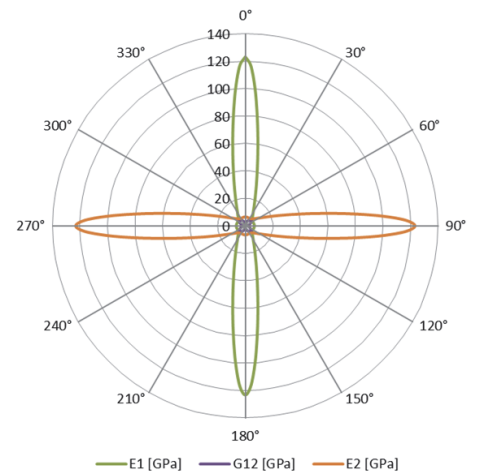

E1 [GPa] - ${ }^{\mathrm{G} 12}[\mathrm{GPa}]-\mathrm{E} 2[\mathrm{GP}$

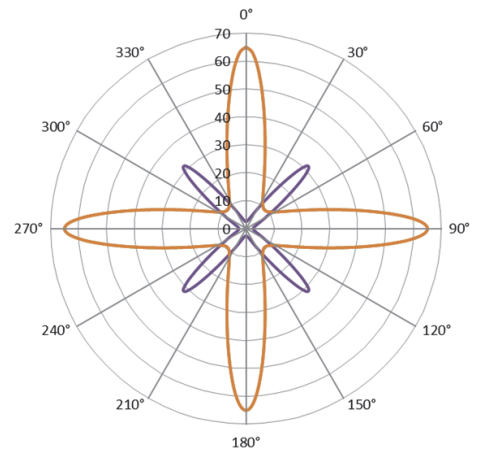

- 1 [GPa] - ${ }^{\mathrm{G} 12}$ [GPa] $-\mathrm{E2}$ [GPa]

(e) cross-ply laminate [0/90]

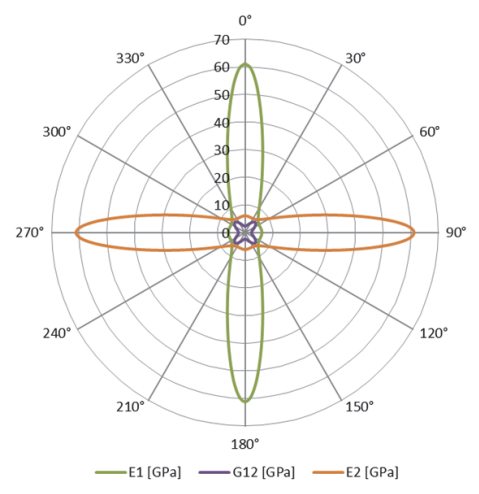

(g) - unidirectional lamina

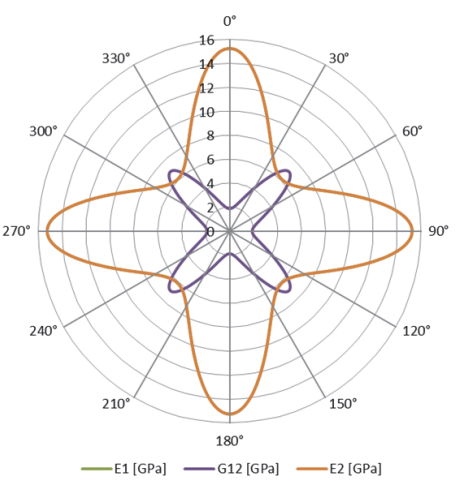

(b) - cross-ply laminate [0/90]

\section{Carbon}

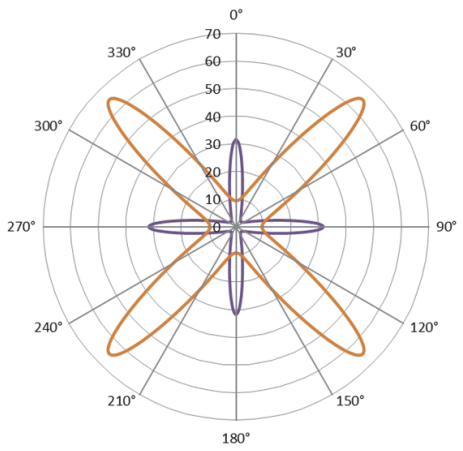

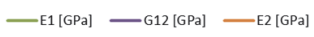

(d) - cross-ply laminate [-45/45]

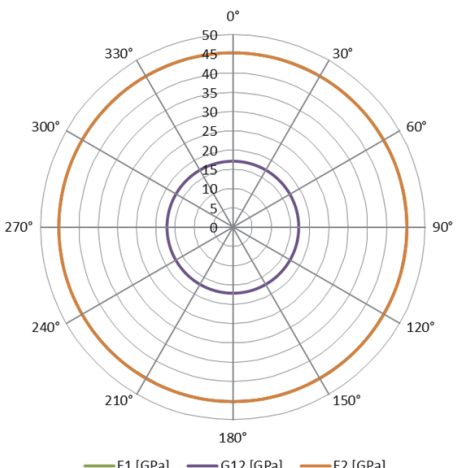

(f) - cross-ply laminate [0/-45/90/45]

\section{Kevlar}

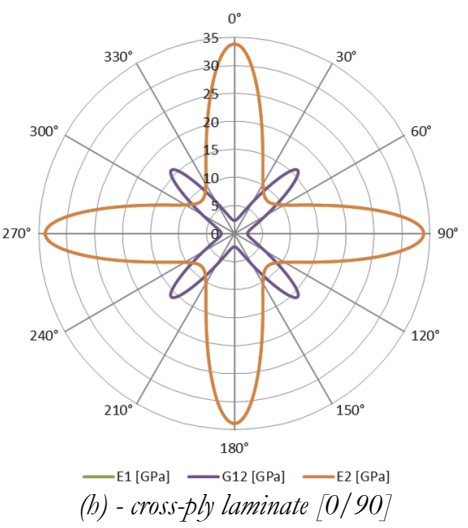

Figure 4: Engineering constants for the A sandwich materials. 


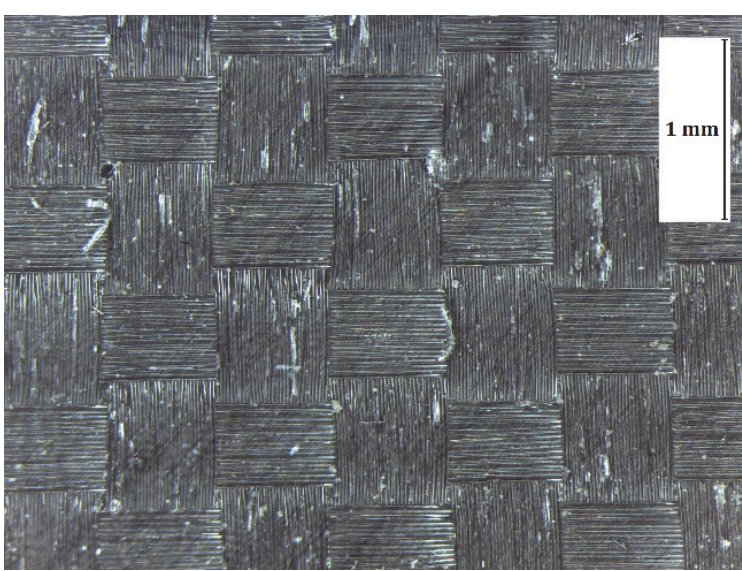

(a)

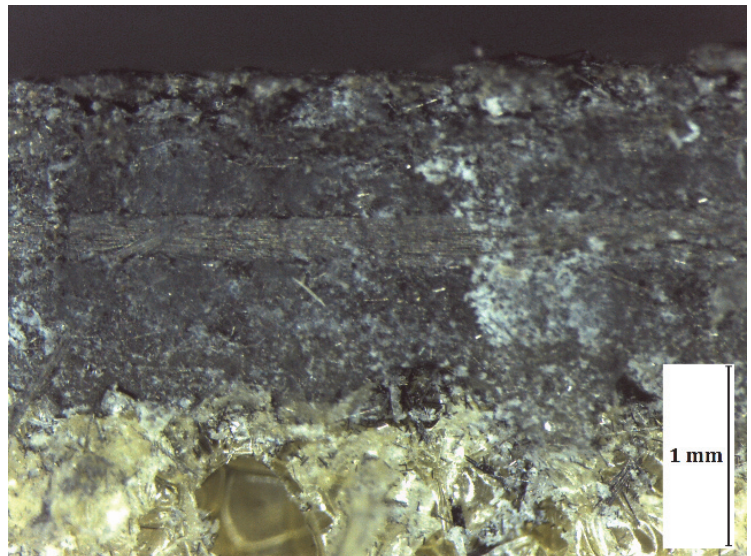

(b)

Figure 5: Microscope pictures of the external skins of A sandwich (a) and along the thickness of B sandwich (b) (zoom factor to 32x).

Tab. 8 shows the mechanical properties of the basic materials of the B sandwich. The basic properties of carbon and resin are the same of the A sandwich, while the core is lighter. The percentage of weight and volume of carbon fibres with respect to the total are the same of the A sandwich (see Tab. 4) and consequently also the mechanical properties of the undirectional laminas.

\begin{tabular}{lccccc}
\hline Basic & $\sigma_{\mathrm{R}}$ & $\mathrm{E}$ & $\mathrm{G}$ & $\nu$ & $\varrho$ \\
materials & {$\left[\mathrm{N} / \mathrm{mm}^{2}\right]$} & {$\left[\mathrm{N} / \mathrm{mm}^{2}\right]$} & {$\left[\mathrm{N} / \mathrm{mm}^{2}\right]$} & $\nu$ & {$\left[\mathrm{kg} / \mathrm{mm}^{3}\right]$} \\
Carbon & 4070 & 248000 & 103330 & 0.20 & $1.80 \mathrm{E}-06$ \\
Core M100 & 2.11 & 110 & 40 & 0.33 & $1.07 \mathrm{E}-07$ \\
Resin & 110 & 3400 & 1310 & 0.30 & $1.20 \mathrm{E}-06$ \\
\hline
\end{tabular}

Table 8: Mechanical properties of the basic materials.

In this case, only the cross-ply laminate of Carbon [0/90] (see Fig. 4 - (e)) differs from the previous ones, since the Carbon $[-45 / 45]$ is equivalent to that of the A sandwich. Tab. 9 shows the mechanical properties of each laminate in the B sandwich.

\begin{tabular}{lcccccc}
\hline Cross-ply laminate & $\sigma_{\mathrm{R} 11}\left[\mathrm{~N} / \mathrm{mm}^{2}\right]$ & $\sigma_{\mathrm{R} 22}\left[\mathrm{~N} / \mathrm{mm}^{2}\right]$ & $\mathrm{E} 1\left[\mathrm{~N} / \mathrm{mm}^{2}\right]$ & $\mathrm{E} 2\left[\mathrm{~N} / \mathrm{mm}^{2}\right]$ & $\mathrm{G} 12\left[\mathrm{~N} / \mathrm{mm}^{2}\right]$ & $\nu_{12}$ \\
Carbon [-45/45] & 801.2 & 801.2 & 9400 & 9400 & 31700 & 0.68 \\
Carbon [0/90] & 1049 & 1048 & 65040 & 65040 & 2530 & 0.03 \\
\hline
\end{tabular}

Table 9: Mechanical properties for each cross-ply laminate in B sandwich.

\section{Experimental set up}

Two different experimental test campaigns have been conducted for each type of sandwich. The four-point bending test has been conducted with an ITALSIGMA machine, having a maximum load capacity of $20 \mathrm{kN}$. The boundary conditions of this test are shown in Fig. 6. The diameter of the rollers was $20 \mathrm{~mm}$ and the lowering speed was set to $0.4 \mathrm{~mm} / \mathrm{s}$. A minimum of three bending tests was conducted for each specimen. The experimental set up for both the specimen types is shown in Fig. 7. 


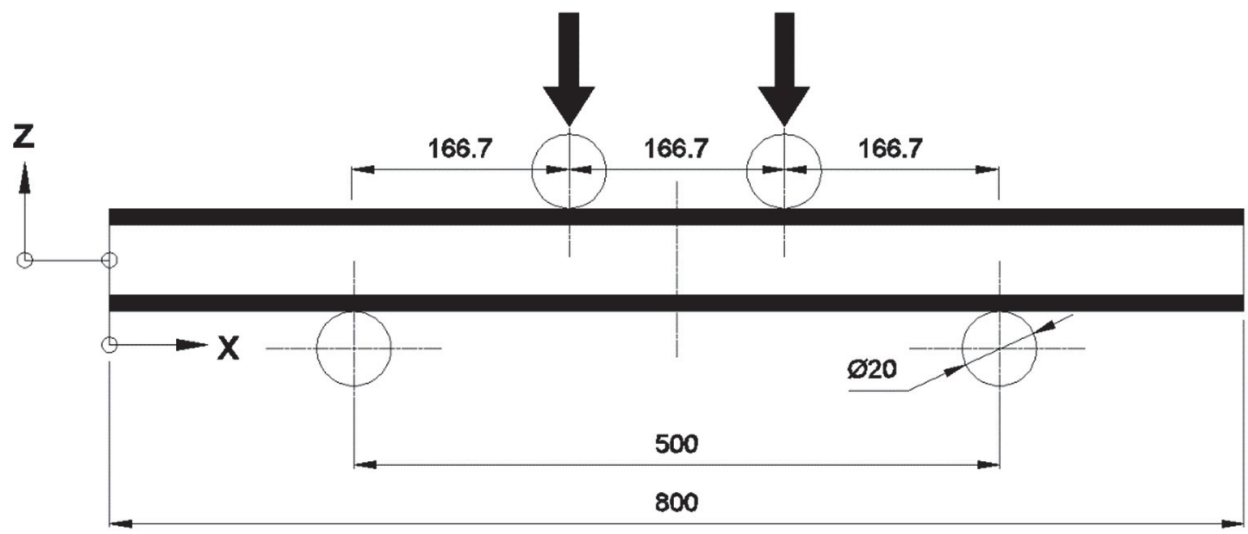

Figure 6: Boundary conditions for four-points bending test.

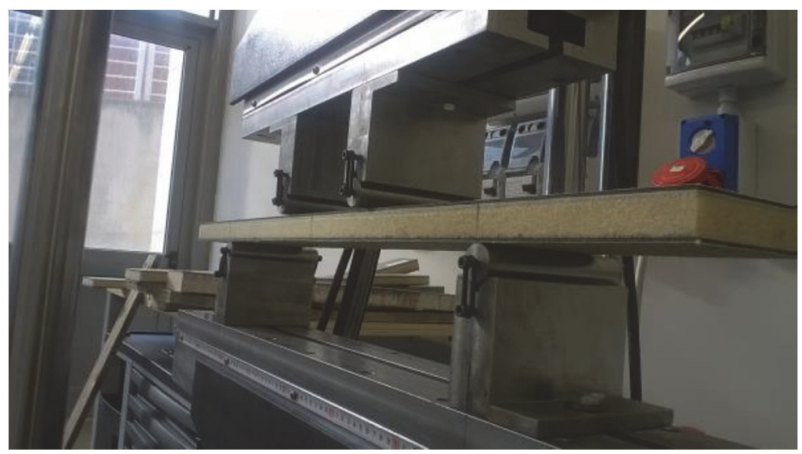

(a)

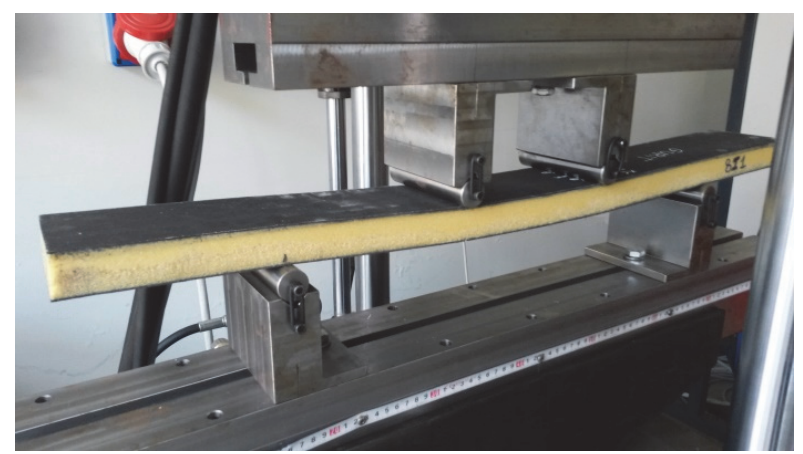

(b)

Figure 7: Initial set up for the A sandwich (a) and B sandwich (b).

In the second experimental campaign, impact drop tests were conducted. These tests have been carried out by using a CEAST Fractovis Plus Machine (Fig. 8). The specimen is held between two steel plates, which present a central hole having a diameter of $70 \mathrm{~mm}$, a thickness of $5 \mathrm{~mm}$ and connected through M5 bolts with no preload (Fig. 9). The plates holding the specimen are then placed on the machine basement without any additional constraint. The needed impact energy can be adjusted by choosing the mass of the striker and the impact speed. The measurement system of the machine allows to know the load of the striker during the impact as a function of time $\mathrm{F}(\mathrm{t})$. Furthermore, it was possible to know the velocity and the impact energy during the test by performing subsequent integrations [20]. A hemispherical striker having a diameter of $20 \mathrm{~mm}$ and a mass of $6.5 \mathrm{~kg}$ was used. Three energy levels were considered: $20 \mathrm{~J}, 40 \mathrm{~J}$ and $60 \mathrm{~J}$. The tests were repeated twice for each energy level.

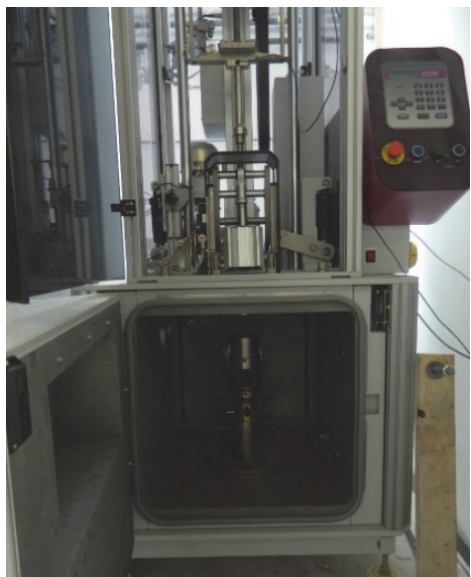

(a)

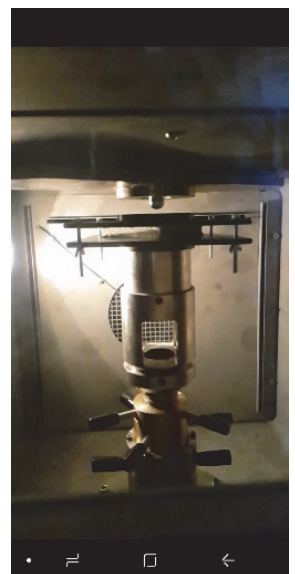

(b)

Figure 8: Drop test machine (a) and impact area detail (b) where it is possible to observe the indenter and the clamping rig 


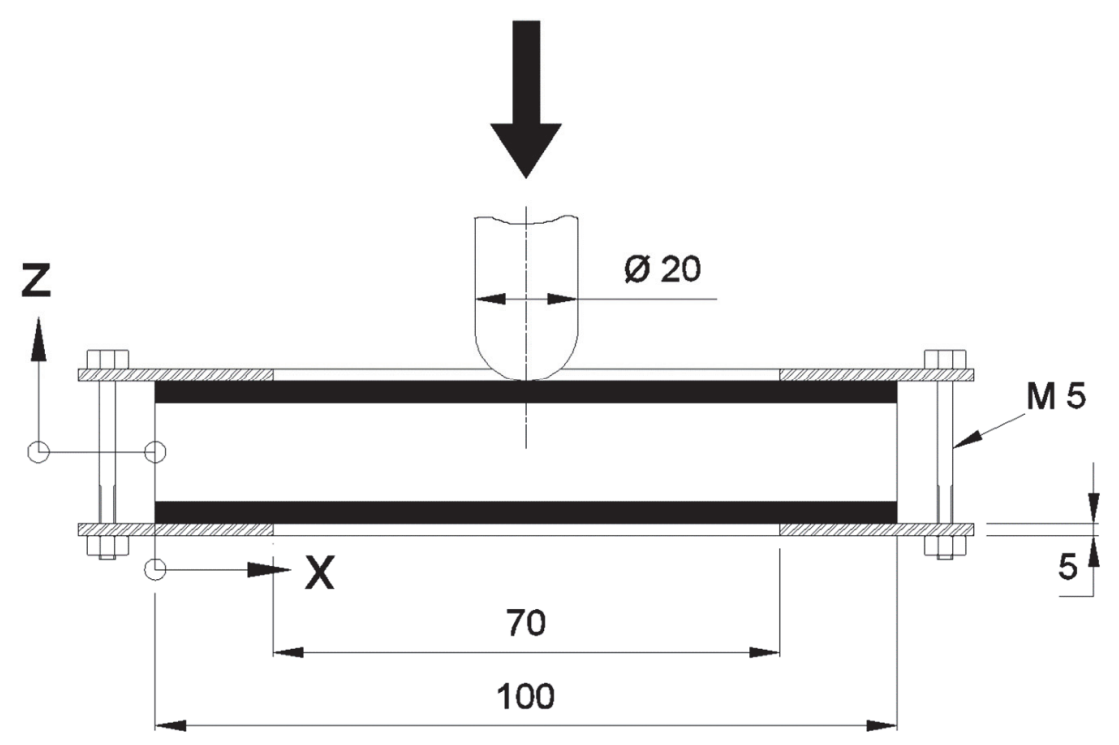

Figure 9: Boundary conditions for impact test.

\section{Numerical models}

A finite element model was developed by exploiting ANSYS Workbench 17.1, to simulate the behaviour of the described composite materials under different loading conditions. In particular, quasi-static bending loading and impact loading were considered. The same modelling choices were made for the material representation under both loading conditions, in order to obtain a general model for these materials. The considered specimens are composed of a thick core of homogenous material and thin skins of composite laminates. The physics of the problem requires a high complexity finite element model to reproduce the anisotropic and not homogeneous material properties, the contact regions, the geometrical non-linearities and the complex constraint conditions. In order to reduce the computational effort, only the thick core was modelled with brick elements (Solid186), while the skins were modelled with shell elements (Shell181). The connection between skins and core was ensured exploiting several bonded contact pairs. This strategy allowed to drastically reduce the number of elements in the volume of the skins, characterized by a ratio between the thickness and the other dimensions of about 100 . The material properties of the core were easily set as isotropic. On the other hand, each skin was modelled as a single surface, even if composed by layers of different materials. The actual properties were then implemented exploiting the "Layered Section" feature of the software, which allows to set the stacking sequence of layers in terms of layer order and thickness. Thus, only the non-isotropic properties of the single layers were set in the material library, while the resulting laminate properties were computed by the software. The loading during the experimental tests were chosen in order to investigate also the region of the load-displacement curve characterized by increasing damage in the specimen. The numerical simulation of the damaged material behaviour is highly challenging, thus the adopted model was aimed at obtaining a rough estimation of the consequences of both core and skins failure. The maximum stress damage initiation criterion was used, and the ultimate stress values (along with all the other material properties) were obtained by the material specifications provided by the manufacturer. Once the damage was initiated, a proportional stiffness reduction was applied to the damaged elements. This reduction coefficient was tuned basing on the comparison between experimental and numerical results of the bending test, exploring the range $0.7-0.95$. In the following, a fraction equal to 0.9 of the undamaged stiffness was set for all the considered materials, which allowed to obtain the best experimental/numerical matching. For generality purposes, the value obtained for the bending test was also used for the impact test. It is worth noting that less reliable numerical results are expected in the regions of the curves were the damage is extended to a great portion of the specimens' volume. Finally, for both bending and impact test simulation, a convergence analysis for mesh dimension was performed: the damage initiation criterion was deactivated, and the maximum Von Mises stress in the specimens was used as convergence parameter. This composite modelling was kept constant for both bending and impact test simulations, since it provided a reliable description of the material behaviour even in such different loading conditions. The simpler quasi-static bending test was simulated first. A static structural analysis was setup by modelling the entire 800x100 specimen, as schematized in Fig. 6 . In order to enhance model accuracy, the machine punches were represented in the model as rigid surfaces. Thus, the specimen skin surfaces were geometrically divided in different areas, to provide contact regions for mesh refinement. The punches were used to represent test constraint (i.e. zero vertical displacement at the lower skin) and the loading (i.e. gradually 
increasing displacement at the upper skin). Thus, a fixed support constraint was applied to the lower punches, and an increasing displacement was imposed to the upper punches. Fig. 10 (a) represents this boundary conditions in the FE model: the core elements were hidden in the figure to better show the skin surfaces, which are geometrically overlapped to the core and would not be easily visible in the full model. The contacts between the punches and the skins were set to frictionless. Fig. 10 (b) shows the displacement map corresponding to the maximum displacement as an example. A more complete result presentation and comparison with experimental analysis is provided in the Section Results and discussion.

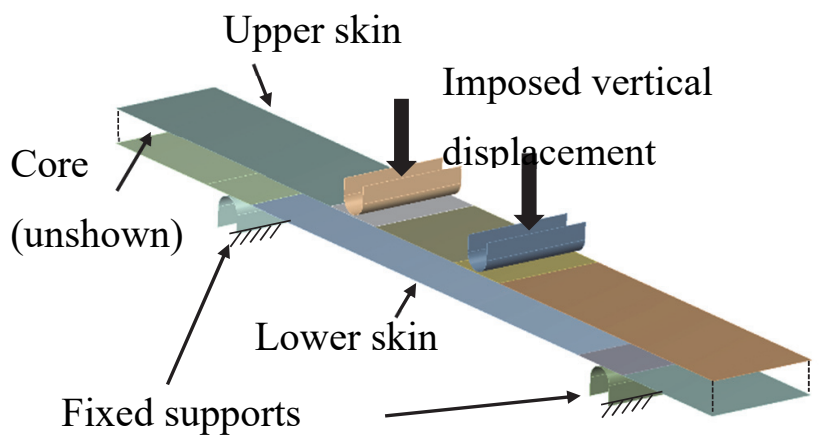

(a)

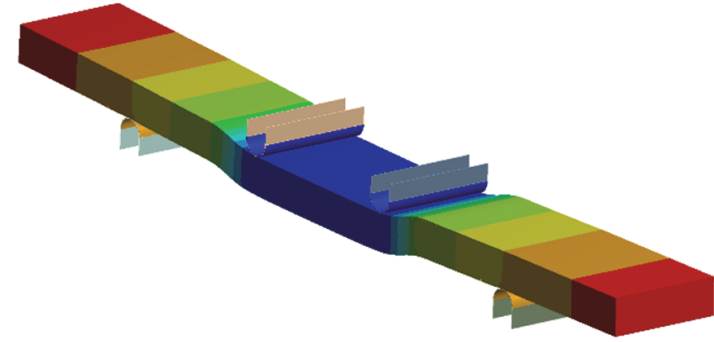

(b)

Figure 10: Bending test modelling: (a) boundary conditions and (b) vertical displacement map.

The impact test, which is less trivial and more interesting, was finally simulated. A transient structural analysis was set up by updating the geometry of the specimen to reproduce the dimensions reported in Fig. 9. A further modelling effort was spent to properly reproduce the boundary conditions. In the actual test, the specimen is held between two bolted plates, which are tightened through four bolted joints with no preload. This assembly is then placed on the top of the testing machine, and no further constraints are applied. Preliminary simulations shown that the direct application of fixed constraints to the specimen surfaces would overestimate the equivalent stiffness, giving great discrepancies with respect to experimental results. To properly reproduce the actual boundary conditions, both upper and lower steel plates were added in the geometrical model, as surface bodies. Standard isotropic homogeneous steel properties were set for both plates. The connection between the plates was modelled through beam elements (Beam188) representing the screws diameter (steel properties). A further surface body was introduced, representing the machine top plane and modelled as an infinitely rigid body. Finally, the striker was modelled as a rigid surface tangent to the specimen skin. A mass element was attached to this surface to represent the actual striker mass. Since the striker in the machine is constrained to move vertically along a single translational degree of freedom, all the other inertia properties were neglected.

The interaction between all the different entities was modelled exploiting different contact regions. The contact between the lower steel plate and the machine plane was set to be frictionless, thus allowing all the relative displacements except interpenetration. The contacts between both steel plates and the specimen, and between the striker and the specimen were set to be frictionless. Remote boundary conditions were applied to the striker to constraint any degree of freedom except the vertical displacement. A fixed constraint was applied to the surface representing the machine top. Finally, the actual loading conditions were determined by imposing an initial velocity to the striker corresponding to the simulated impact energy. Fig. 11 (a) shows a section view of the described FE model, reporting the main parts (the surface bodies are repented as thick bodies just for graphical purposes, while they are meshed with shell elements). Fig. 11 (b) shows the vertical displacement map corresponding to the maximum displacement as an example. A more complete results presentation and comparison with experimental analysis is provided in the next section.

\section{RESULTS AND DISCUSSION}

7 he four-point bending tests have been carried out on three specimens for each sandwich typology. The experimental results for each kind of sandwich are reported in Tab. 10 (mean values). The considered quantities, derived from the load-displacement curve, are: the maximum load before the failure (i.e. the peak of the curve), the deflection at the maximum load and the specimen stiffness (i.e. the slope of the curve at the origin). The two specimens have different weight and lay-up sequence but both have to respect the same rules. This discrepancy in design idea leads to a different 
result of the bending tests. The A sandwich has a higher stiffness and the peak load before the failure is almost double of that of the B sandwich.

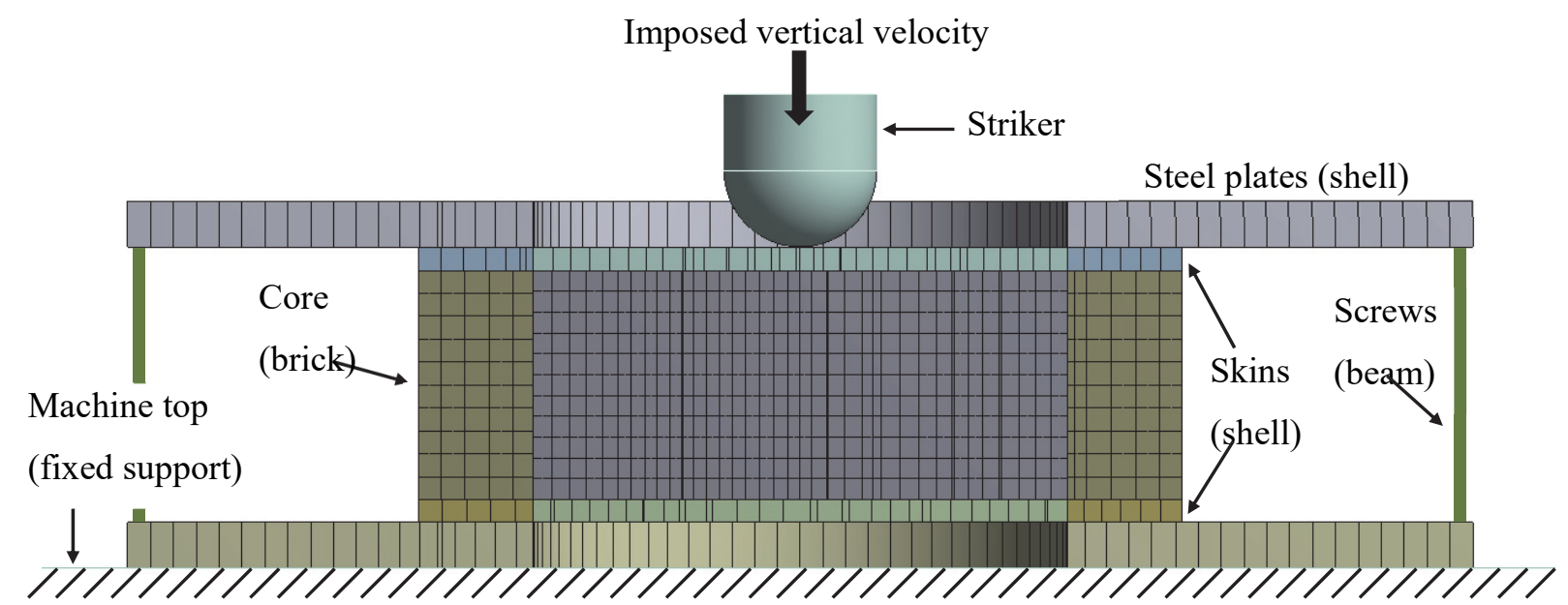

(a)

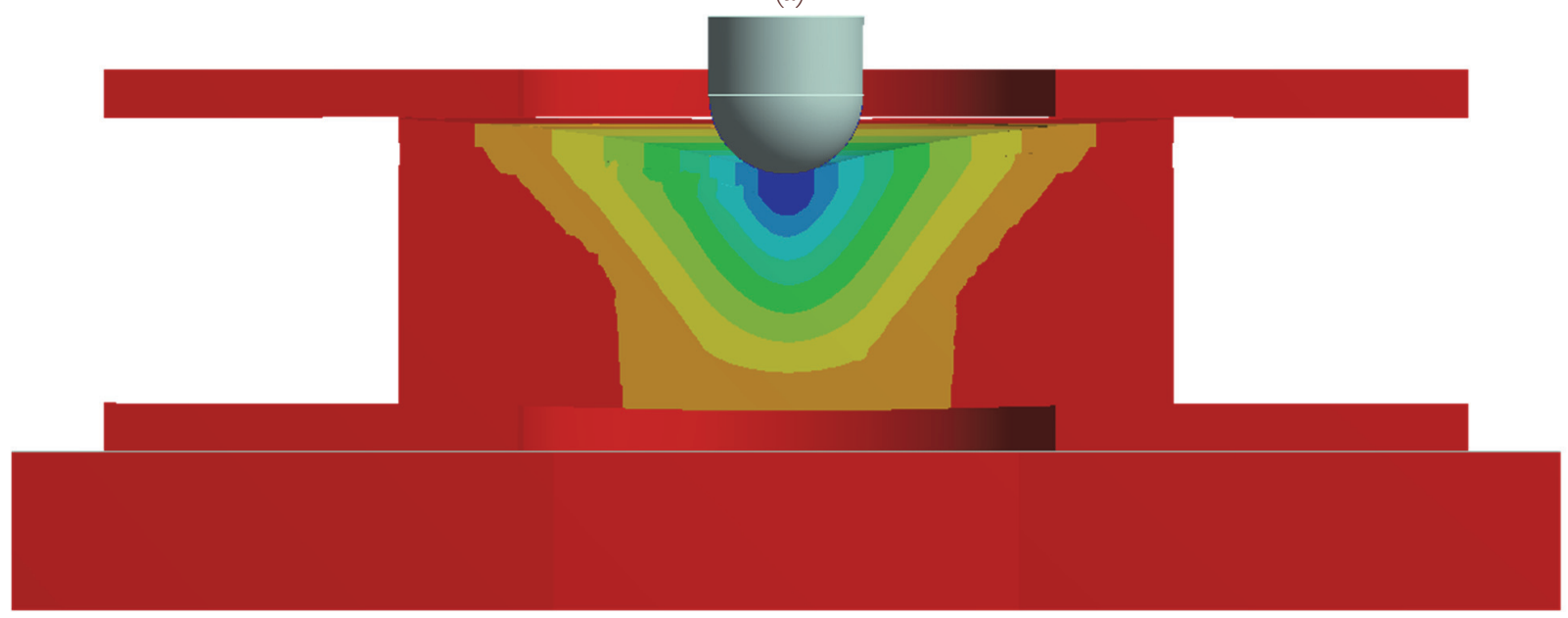

(b)

Figure 11: Drop test simulations: (a) FE model and (b) vertical displacements map.

\begin{tabular}{lcc}
\hline & A Sandwich & B Sandwich \\
Maximum load before failure $[\mathrm{kN}]$ & 14.07 & 7.53 \\
Deflection to maximum load $[\mathrm{mm}]$ & 13.59 & 12.90 \\
Stiffness $[\mathrm{kN} / \mathrm{mm}]$ & 0.59 & 0.33 \\
\hline
\end{tabular}

Table 10: Mean values for specimens of A sandwich and B sandwich.

The experimental results were then compared with numerical analysis in terms of load-displacement curve, as shown in Fig. 12. The FE model gave a good representation of the linear behaviour before damage, and also a reliable estimation of damage initiation. When the damage level increased, anyway, convergence problems arose, which limited the simulation range. 


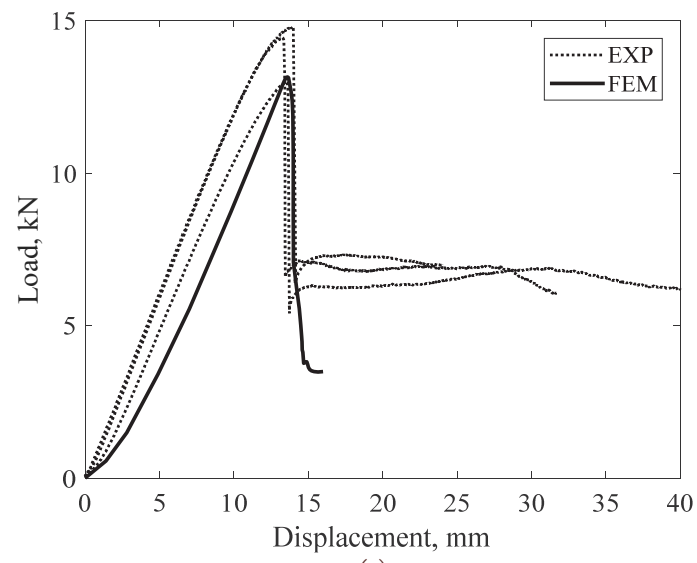

(a)

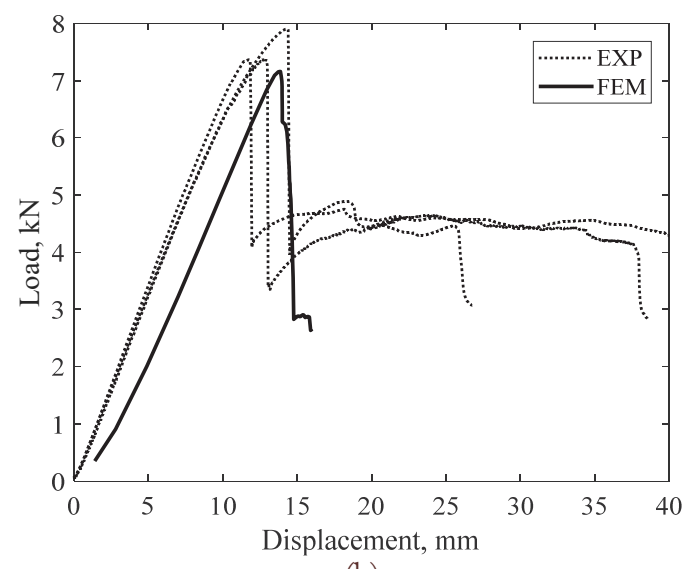

(b)

Figure 12: A sandwich (a) and B sandwich (b): FEA and Experimental comparison of the 4 point flexural test.

Concerning the impact tests, the load-displacement curves were used again to derive the considered quantities: absorbed energy, stiffness, peak force and maximum displacement of the striker. The ratio between the Impact Energy and Absorbed Energy (damage degree), as shown by Belingardi [16], helps to understand if there is rebound (value less than 1) or perforation and then failure (equal to 1) during the test. The impact tests have been carried out on three specimens for each sandwich typology and each impact energy (i.e. 18 tests in total). The mean values of the considered quantities are reported in Tab. 11 and Tab. 12 for A sandwich and B sandwich respectively.

\begin{tabular}{lrrr}
\hline & \multicolumn{3}{c}{ A sandwich } \\
Impact Energy J] & 20.0 & 40.0 & 60.0 \\
Absorbed Energy J] & 17.6 & 35.3 & 56.1 \\
Ratio Impact/absorbed Energies & 0.9 & 0.9 & 0.9 \\
Stiffness [N/mm] & 1170.3 & 2015.3 & 2011.0 \\
Peak Force [N] & 6736.2 & 7854.0 & 7693.0 \\
Maximum displacement [mm] & 5.57 & 6.86 & 10.09 \\
\hline
\end{tabular}

Table 11: Mean values for specimens of A sandwich.

\begin{tabular}{lrrr}
\hline & \multicolumn{3}{c}{ B sandwich } \\
Impact Energy J] & 20.0 & 40.0 & 60.0 \\
Absorbed Energy J] & 16.1 & 38.1 & 60.0 \\
Ratio Impact/absorbed Energies & 0.8 & 0.9 & 1.0 \\
Stiffness [N/mm] & 2429.1 & 1362.1 & 1394.6 \\
Peak Force [N] & 7154.6 & 6212.4 & 6499.1 \\
Maximum displacement [mm] & 4.08 & 10.20 & 19.78 \\
\hline
\end{tabular}

Table 12: Mean values for specimens of B sandwich. 
The impact tests show that the peak force and the stiffness are nearly independent from the impact energy, as well known from literature [20,21]. The absorbed energy is very similar between A and B sandwiches, as long as the sandwiches are not yet damaged (damage degree less than 1). To the maximum energy level tested there is a difference between the specimens. The damage degree of the Specimen B is equal to 1 and this states a perforation and complete failure. Fig. 13 reports the comparison between numerical and experimental results, again in terms of load-displacement curve.

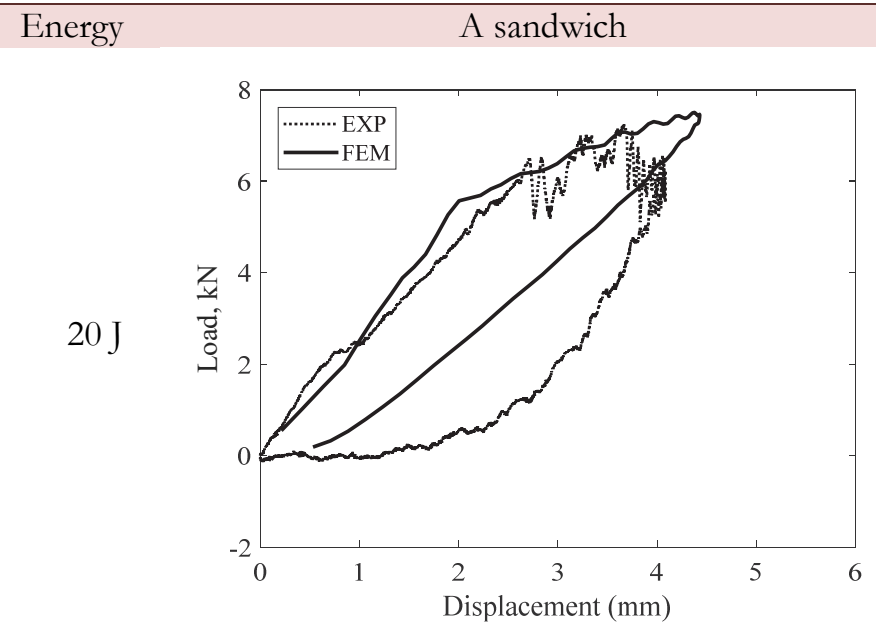

(a)

$40 \mathrm{~J}$

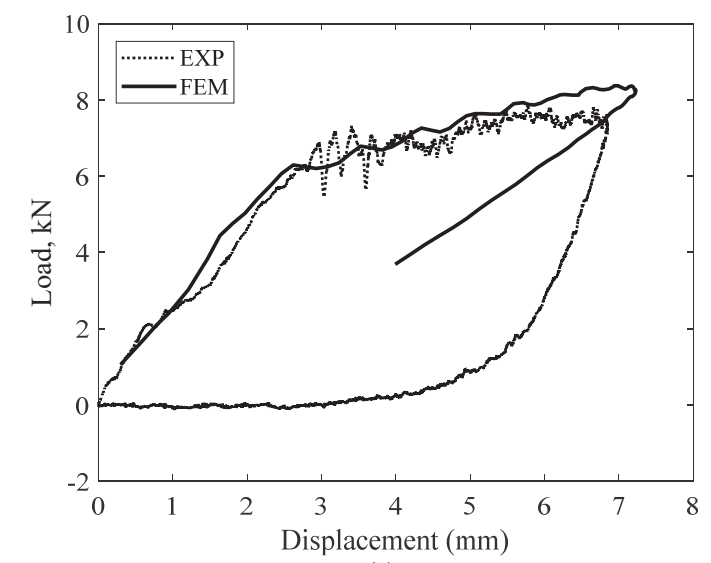

(c)

$60 \mathrm{~J}$

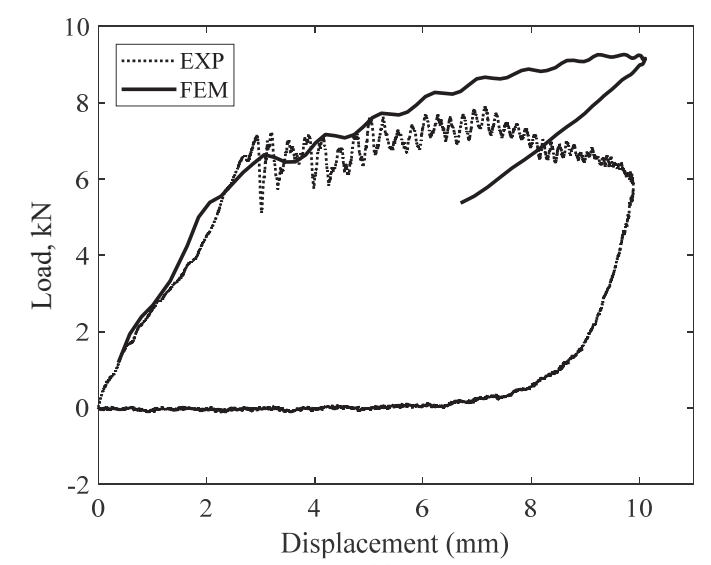

(e)
B sandwich

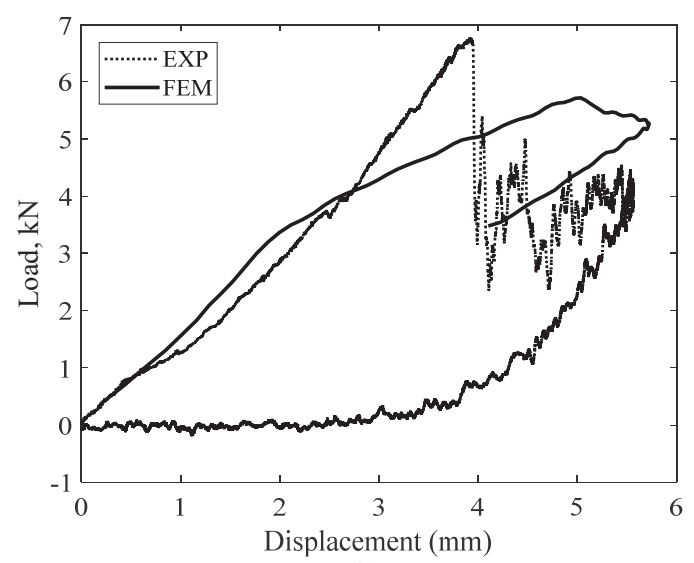

(b)

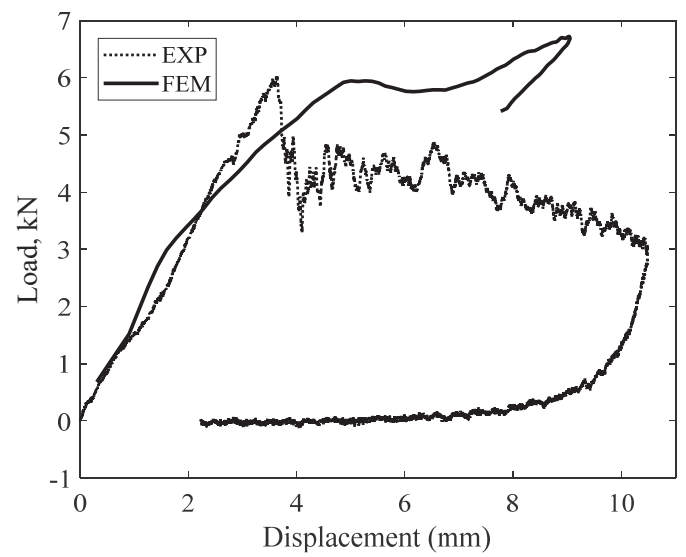

(d)

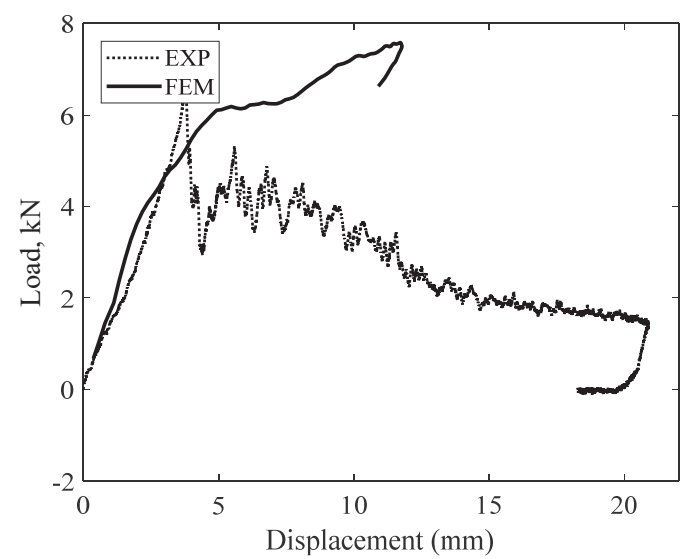

(f)

Figure 13: A sandwich and B sandwich: FEA and Experimental comparison of impact tests at $20 \mathrm{~J}$ (a) and (b), $40 \mathrm{~J}$ (c) and (d), $60 \mathrm{~J}$ (e) and $(\mathrm{f})$. 
A good correspondence between the linear regions (before damage initiation) can be depicted in all the performed simulations. Moreover, the simulations of the A sandwich provided reliable results also concerning the damage initiation, the specimen stiffness after damage and, also, the maximum elongation before spring-back. On the other hand, the simulations of the B sandwich shown less reliable estimation of the material behaviour after damage. This is maybe due to the lower strength of the material of the B sandwich, which experience a higher damage level which is hardly reproducible through numerical modelling.

In order to compare the two specimens, considering also the respectively weights, the specific quantities have been calculated. This quantities are obtained as the ratio between the generic quantity and the weight of the specimen. A comparison of the behaviour of the two sandwich typologies has been showed in Tab. 13 by means of the ratios of each quantity between the two materials (the impact values refer to the tests at $60 \mathrm{~J}$ ).

\begin{tabular}{lcc}
\hline & Test & Ratio A/B \\
Weight & & 1.71 \\
Maximum load before failure & 4-point bending & 1.87 \\
Specific maximum load & 4-point bending & 1.09 \\
Deflection to maximum load & 4-point bending & 1.05 \\
Specific deflection & 4-point bending & 0.61 \\
Stiffness & 4-point bending & 1.76 \\
Specific stiffness & 4-point bending & 1.03 \\
\hline Stiffness & Impact (60 J) & 1.44 \\
Specific stiffness & Impact (60 J) & 0.84 \\
Peak Force & Impact (60 J) & 1.18 \\
Specific peak force & Impact (60 J) & 0.69 \\
Maximum displacement & Impact (60 J) & 0.51 \\
Specific maximum displacement & Impact (60 J) & 0.30 \\
\hline
\end{tabular}

Table 13: Comparison between A and B sandwich values.

It is possible to observe that the maximum load before failure for the A sandwich is almost twice than for the B sandwich. However, the specific maximum load is very similar. Conversely, the peak force derived from impact tests is very similar for both sandwiches and, consequently, the ratio between specific values is lower than one. Moreover, the specific bending stiffness of the two sandwiches is almost the same, while the B sandwich has a higher specific impact stiffness. Finally, the absolute values of the maximum displacement are very similar in bending test, while a ratio of two was found in the impact test.

The comparison shows that the bending and impact behaviours of the specimens are not directly connected. This highlights the importance of a reliable FE model: a simple experimental campaign can be conducted to tune and validate the model, while many different testing conditions can be numerically simulated, thus drastically reducing testing time and costs.

Finally, it was possible to conclude that the B sandwich (lighter material), has similar specific bending performances but better specific impact behaviour with respect to A sandwich. This result is interesting in order to well balance weight and safety, to obtain the best performances, that is crucial in the world of competition sports.

\section{CONCLUSIONS}

$\mathrm{I}$ $\mathrm{n}$ this paper, two different kinds of sandwiches for UIM powerboats application were considered, belonging to the same competition class. These materials are very performing and innovative and they are yet very poorly studied. Firstly, an experimental campaign was conducted to assess both quasi-static and dynamic behaviour of the materials. The 
results were finally exploited to validate a FE model purposely developed for such complex and non-isotropic composite materials.

The two specimens have been manufactured complying with the same rulebook. However the behaviour during the bending tests is quite different. As shown in Section 2.1, the design idea of the two shipbuilders is different and this discrepancy leads to a different stacking sequence and a final different weight of the two composites (and also to different manufacturing costs). In absolute terms (without considering the respective weights), the A sandwich has a better mechanical behaviour than B sandwich. This difference is annulled or, in some cases, reversed if specific quantities are considered. The same trend is highlighted during the impact tests. These experimental tests suggest that the great flexibility of these materials can lead to different final products designed for the same purpose. In order to find the right compromise (costs, mechanical efficiency, environmental impacts), is fundamental and useful to have a tool, as FE, in preliminary stage, for evaluating different design solutions in different loading conditions and in rapid way. The FE model has been validated through both four-point bending and impact tests. The models provided a reliable representation of the linear behaviour of the material before damage, and an acceptable estimation of the damage growth at higher energy levels. The developed model represents a valuable tool, which can help engineers to make design choices before performing experimental activity, thus allowing to save time and costs and to optimize performances faster. Also, as a future development, the FE model could be exploited in a topological optimization tool to obtain the best layouts for thickness, materials, fibres orientation and core size for specific applications.

The experimental and numerical tests showed that there is not a direct correlation between bending and impact properties of the sandwiches. Thus, the importance of a reliable FE model was further highlighted, since the material response under particular conditions cannot be inferred from other testes. It must be underlined that the UIM rules, at the moment, require only four-point quasi static bending tests. Consequently, in order to enhance the safety of drivers by maximizing the impact strength of the cockpit and the ability to absorb energy, the UIM rules could surely be improved, in the future, by providing specific impact characterization compliances.

\section{ACKNOWLEDGMENTS}

$\checkmark$ he authors wish to thank Mr. Tom Stanley of the Union Internationale Motonautique (UIM) for providing the samples and Mr Sergio Abrami for the precious comments and suggestions.

\section{REFERENCES}

[1] Ashby, M.F., Bush, S.F., Swindells, N., Bullough, R., Ellison, G., Lindblom, Y., Cahn, R.W., Barnes, J.F. (1987). Technology of the 1990s: Advanced Materials and Predictive Design [and Discussion], Philos. Trans. R. Soc. A Math. Phys. Eng. Sci., 322(1567), pp. 393-407. DOI: 10.1098/rsta.1987.0059.

[2] Gibson, R.F. (2010). A review of recent research on mechanics of multifunctional composite materials and structures, Compos. Struct., 92(12), pp. 2793-2810. DOI: 10.1016/j.compstruct.2010.05.003.

[3] Kelly, A., Buresch, F.E., Biddulph, R.H. (1987). Composites for the 1990s [and Discussion], Philos. Trans. R. Soc. A Math. Phys. Eng. Sci., 322(1567), pp. 409-23. DOI: 10.1098/rsta.1987.0060.

[4] Soutis, C. (2005). Fibre reinforced composites in aircraft construction, Prog. Aerosp. Sci., 41(2), pp. 143-151. DOI: $10.1016 /$ j.paerosci.2005.02.004.

[5] Ding, M., Liu, J., Liu, B., Wang, X., Li, T., Cao, D. (2016).On the Development of Automotive Composite Material Rear Bumper Beam. Proceedings of SAE-China Congress 2015, pp. 297-308.

[6] Kimpara, I. (1991). Use of advanced composite materials in marine vehicles, Mar. Struct., 4(2), pp. 117-127. DOI: 10.1016/0951-8339(91)90016-5.

[7] Timmis, A.J., Hodzic, A., Koh, L., Bonner, M., Soutis, C., Schäfer, A.W., Dray, L. (2015). Environmental impact assessment of aviation emission reduction through the implementation of composite materials, Int. J. Life Cycle Assess., 20(2), pp. 233-243. DOI: 10.1007/s11367-014-0824-0.

[8] Witik, R.A., Payet, J., Michaud, V., Ludwig, C., Manson, J.A.E. (2011). Assessing the life cycle costs and environmental performance of lightweight materials in automobile applications, Compos. Part A Appl. Sci. Manuf., 42(11), pp. 1694 1709. DOI: 10.1016/j.compositesa.2011.07.024. 
[9] Koronis, G., Silva, A., Fontul, M. (2013). Green composites: A review of adequate materials for automotive applications, Compos. Part B Eng., 44(1), pp. 120-127. DOI: 10.1016/j.compositesb.2012.07.004.

[10] Boland, C.S., De Kleine, R., Keoleian, G.A., Lee, E.C., Kim, H.C., Wallington, T.J. (2016). Life Cycle Impacts of Natural Fiber Composites for Automotive Applications: Effects of Renewable Energy Content and Lightweighting, J. Ind. Ecol., 20(1), pp. 179-189. DOI: 10.1111/jiec.12286.

[11] Barone, S., Cucinotta, F., Sfravara, F. (2017).A comparative Life Cycle Assessment of utility poles manufactured with different materials and dimensions. Advances on Mechanics, Design Engineering and Manufacturing, Springer International Publishing, pp. 91-99.

[12] Kim, S.-Y., Shim, C.S., Sturtevant, C., Kim, D. (Dae-W., Song, H.C. (2014). Mechanical properties and production quality of hand-layup and vacuum infusion processed hybrid composite materials for GFRP marine structures, Int. J. Nav. Archit. Ocean Eng., 6(3), pp. 723-736. DOI: 10.2478/ijnaoe-2013-0208.

[13] Hinton, M.J., Soden, P.D. (1998). Predicting failure in composite laminates: the background to the exercise, Compos. Sci. Technol., 58(7), pp. 1001-1010. DOI: 10.1016/S0266-3538(98)00074-8.

[14] Belouettar, S., Abbadi, A., Azari, Z., Belouettar, R., Freres, P. (2009). Experimental investigation of static and fatigue behaviour of composites honeycomb materials using four point bending tests, Compos. Struct., 87(3), pp. 265-273. DOI: $10.1016 /$ j.compstruct.2008.01.015.

[15] Manalo, A.C., Aravinthan, T., Karunasena, W., Islam, M.M. (2010). Flexural behaviour of structural fibre composite sandwich beams in flatwise and edgewise positions, Compos. Struct., 92(4), pp. 984-995.

DOI: 10.1016/j.compstruct.2009.09.046.

[16] Belingardi, G., Vadori, R. (2002). Low velocity impact tests of laminate glass-fiber-epoxy matrix composite material plates, Int. J. Impact Eng., 27(2), pp. 213-229. DOI: 10.1016/S0734-743X(01)00040-9.

[17] Belingardi, G., Vadori, R. (2003). Influence of the laminate thickness in low velocity impact behavior of composite material plate, Compos. Struct., 61(1-2), pp. 27-38. DOI: 10.1016/S0263-8223(03)00027-8.

[18] Russo, A., Zuccarello, B. (2007). Experimental and numerical evaluation of the mechanical behaviour of GFRP sandwich panels, Compos. Struct., 81(4), pp. 575-586. DOI: 10.1016/j.compstruct.2006.10.007.

[19] Hassan, M.A., Naderi, S., Bushroa, A.R. (2014). Low-velocity impact damage of woven fabric composites: Finite element simulation and experimental verification, Mater. Des., 53, pp. 706-718. DOI: 10.1016/j.matdes.2013.07.068.

[20] Cucinotta, F., Paoli, A., Risitano, G., Sfravara, F. (2017). Optical measurements and experimental investigations in repeated low-energy impacts in powerboat sandwich composites, Proc. Inst. Mech. Eng. Part M J. Eng. Marit. Environ., pp. 147509021772061. DOI: 10.1177/1475090217720619.

[21] Cucinotta, F., Guglielmino, E., Risitano, G., Sfravara, F. (2016). Assessment of Damage Evolution in Sandwich Composite Material Subjected to Repeated Impacts by Means Optical Measurements, Procedia Struct. Integr., 2, pp. 3660-3667. DOI: 10.1016/j.prostr.2016.06.455.

\section{NOMENCLATURE}

\begin{tabular}{lcc}
\hline Symbol & Definition & Unit \\
$\sigma_{\mathrm{R}}$ & Ultimate stress strength & {$\left[\mathrm{N} / \mathrm{mm}^{2}\right]$} \\
E & Young's Modulus & {$\left[\mathrm{N} / \mathrm{mm}^{2}\right]$} \\
$G$ & Shear Modulus & {$\left[\mathrm{N} / \mathrm{mm}^{2}\right]$} \\
$\nu$ & Poisson's ratio & - \\
$\varrho$ & Weight density & {$\left[\mathrm{kg} / \mathrm{mm}^{3}\right]$} \\
w & Weight fraction & - \\
$\mathrm{v}$ & Volume fraction & - \\
\hline
\end{tabular}

